\title{
Dilemas entre el contexto de formulación y el ejercicio y la vivencia de los derechos humanos en la escuela
}

\author{
Nelson Ernesto López Jiménez ${ }^{1}$ \\ Universidad Surcolombiana, Colombia \\ nelopez53@gmail.com
}

Analizar el dilema que se presenta cuando se interroga sobre si los Derechos Humanos son contenidos o son vivencias, ejercicios, prácticas y realizaciones sociales y humanas requiere inicialmente explicitar el concepto de formación ${ }^{2}$ como un proceso que desborda las dinámicas escolares y que descarta la concepción de la escuela como la única institución que forma; es necesario integrar otros contextos culturales que también forman y que deben ser tenidos en cuenta cuando se afirma que el estudiante es un sujeto de derechos. Estos contextos son la familia, el trabajo, el barrio, el grupo cultural y artístico, es decir lo que se referencia cuando se utiliza la expresión "mundo de la vida"

Cuando los Derechos Humanos ${ }^{3}$ son concebidos como contenidos o temas a dictar, se hace una clara apología de la concepción restringida de formación (en la actualidad, hegemónica) que genera lamentablemente una orientación hacia el "aprender los derechos humanos", y se advierte una tensión estructural con la afirmación de que el niño o la niña son sujetos de derechos humanos que deben "vivir esos derechos y no aprenderlos". No se trata de que sepan que es la libertad, el respeto a la otredad, la no discriminación, el derecho a un buen nombre, sino que efectivamente sean testimonio de tales derechos, es decir, que sea libre, autónomo, asertivo, tolerante, deliberante, no perseguido.

Si se toma como referente de análisis la anterior ilustración de la problemática de la formación, resulta indiscutible y preocupante la tensión existente entre el contexto de formulación de los Derechos Humanos y el contexto de realización y vivencia de los mismos en la escuela ${ }^{4}$. En esta línea de análisis es oportuno señalar algunos interrogantes que invitan a posicionarnos en el contexto de este dilema:

- ¿Cuál es el contexto y como se entiende la escuela en el marco de la problemática de los Derechos Humanos?

\footnotetext{
${ }^{1}$ Post-doctor en Ciencias Sociales, Niñez y Juventud, Doctor en Educación área Lenguaje y Educación. Docente de tiempo completo Universidad Surcolombiana. Director Grupo de Investigación PACA Categoría A de Colciencias. Investigador Sénior 2017. Presidente del CICE Centro de Investigación en Calidad de la Educación de Colombia, adscrito a CLACSO.

2 "La formación se entiende como la interacción entre un campo de conocimientos y un campo de problemas que generan características determinantes de los procesos a partir de la duda, la incertidumbre y la creación colectiva que su desarrollo comporta" Modernización Curricular de la Universidad Surcolombiana, Nelson López (2011).

3 "Los derechos humanos son el conjunto de cualidades o atributos propios del ser humano originados en su dignidad como persona y como miembro de la sociedad. De hecho, dichas cualidades o atributos que expresan la dignidad intrínseca del ser humano son el fundamento al que hacen referencia las diferentes declaraciones oficiales de derechos a lo largo de la historia" Abraham Magendzo y Jorge Manuel Pavéz. Educación en Derechos Humanos: una propuesta para educar desde la perspectiva controversial. (2015).

4 "La educación en derechos humanos en América Latina comenzó a desarrollarse en la década de 1980, desde los movimientos sociales y con estos: movimiento de educación popular, movimientos por la paz, movimientos feministas, movimientos de trabajadores,
} 
- ¿La escuela está comprometida con la defensa de los Derechos Humanos del niño y la niña como sujetos de derechos? Si existe ese compromiso, ¿cómo se evidencia o demuestra?

- ¿Quién o quienes escogen las problemáticas que se trabajan en torno a los Derechos Humanos en la escuela?, ¿Qué pasa con las problemáticas que no se incluyen?

- ¿La enseñanza de los DD.HH. en la escuela tiene en cuenta la realidad y el contexto de cada Institución Educativa?

- ¿Cómo se fomentan la identidad y el respeto de los estudiantes ante los grupos étnicos, comunidades religiosas, clases sociales, las diferencias de género, entre otras?

- ¿Se puede afirmar que la escuela vulnera los DD.HH. de los estudiantes?, ¿Por qué?

Dada la complejidad existente entre el proceso curricular y los Derechos Humanos no se puede pensar en una única salida a la problemática analizada, no obstante, se considera conveniente retomar propuestas alternativas que logran avanzar en una concepción diferente de la escuela, sus integrantes, su intencionalidad, su procesos y sus responsabilidad en la búsqueda de la plena libertad, la autonomía, la dignidad y la justicia social.

Des-asignaturizar la formación de los Derechos Humanos en la escuela se convierte en una expresión de respeto y seriedad para lograr su vivencia, ejercicio, disfrute y asunción por parte de todos sus integrantes. Los currículos no pueden ser cerrados y jerarquizados soportados en asignaturas y materias aisladas y atomizadas, deben sustentarse en procesos de investigación e indagación permanentes. El enfoque pedagógico de transmisión es una muestra de atraso y obsolescencia de las prácticas pedagógicas ${ }^{5}$ y del proceso formativo, que origina una identidad heteronómica, dependiente y descontextualizada del estudiante.

La tensión existente entre el desarrollo curricular y los Derechos Humanos nos advierte la importancia de orientar la actividad académica hacia la acción práctica y la consolidación de nuevos y alternativos tipos de formación ${ }^{6}$, como lo son la enseñanza problemática, el aprendizaje por proyectos, la flexibilidad curricular, académica, administrativa y pedagógica desarrolladas a partir de núcleos temáticos y problemáticos, asumidos como "estrategia curricular que integra un conjunto de problemas con conocimientos académicos y cotidianos afines y posibilita definir líneas de investigación en torno al objeto de transformación".

En este sentido, EL ENFOQUE
PEDAGÓGICO DE
SISTEMÁ - EPIS-
alternativa diseñada por el Grupo de Investigación PACA) se plantea como sustituto del "modelo pedagógico de transmisión", concibe la formación como la síntesis creativa entre un campo de conocimientos y un campo de problemas que genera características determinantes de los procesos a partir de la duda, la incertidumbre y la creación colectiva que su desarrollo comporta.

El EPIS, pretende hacer un análisis de las estructuras administrativas, académicas, curriculares, pedagógicas y culturales de las

movimientos de derechos de las minorías, etc. Tomó como base el pensamiento de Paulo Freire, quien trabajó con convicción de que es a través del diálogo como las personas aprenden y toman conciencia de que son sujetos de derecho". Abraham Magendzo, Educación en derechos humanos: Estrategia pedagógica-didáctica centrada en la controversia, (2015).

${ }^{5}$ Entendidas como "procedimientos, estrategias y prácticas que regulan la interacción, la comunicación, el ejercicio del pensamiento, del habla, de la visión, de las posiciones, oposiciones y disposiciones de los sujetos en la escuela" Mario Díaz Villa - De la Práctica 6 "La transformación de las prácticas pedagógicas de formación centradas en el aprendizaje implica el desarrollo de acciones problematizadoras, integradoras, investigativas, participativas o socializantes, que favorecen la estructuración de los conocimientos y las relaciones" Nelson López, Modernización curricular de la Universidad Surcolombiana, (2011). 
Instituciones Educativas asumidas como "verdaderas problemáticas" para posteriormente evaluarlas e intervenirlas, en la perspectiva de alcanzar pertenencia social y pertinencia académica, como base de la calidad y excelencia académica. Además, plantea una oposición directa a los procesos académicos enciclopédicos y sugiere la construcción de proyectos alternativos de formación que se sustenten en procesos de indagación permanente, donde las relaciones entre la comunidad académica sean horizontales, es decir, se reconozcan las capacidades y habilidades del otro, sus planteamientos y sus construcciones de saberes.

El enfoque plantea trabajar sobre espacios contradictorios, tensionantes, problemáticos, entendidos como experienci-

as pedagógicas (prácticas) organizadas para investigar y resolver conflictos, dudas, inconsistencias que se presentan enredados en el mundo de la vida (Hoyos: 2003); como un organizador del currículo; una estrategia de enseñanza que compromete activamente a los estudiantes en tanto responsables en la solución de la inconsistencia o irregularidad presentada y plantea la existencia de tres niveles de ejecución recíprocos, complementarios e interdependientes. Estos niveles hacen alusión a las dimensiones macro, meso y micro.

Un primer proceso en el desarrollo del EPIS, tiene relación directa con la contextualización, es el resultado del dialogo o la interacción entre la dimensión macro de la realidad con la dimensión micro de la misma. En este nivel "macro" encontramos, por ejemplo, los impactos o influencias y determinaciones relacionados con las políticas de educación a nivel internacional, estas políticas ejercen una marcada influencia sobre las políticas educativas a nivel nacional e incluso en algunos casos con las políticas educativas a nivel institucional.

El nivel "Meso" está estructurado por los propósitos y los perfiles de formación que se pretenden lograr, se hace indispensable construir un conjunto de preguntas que hacen referencia a problemáticas relacionadas con los retos de la construcción de una escuela nueva, la problemática comienza a complejizarse cuando los perfiles de formación que son las características identitarias de todo profesional, son resultado de una copia o reproducción acrítica y no de un proceso de investigación soportado en la indagación sistemática.

Como resultado del análisis de las fases macro y meso aparece una tercera fase muy concreta que hace referencia al nivel micro, que alude problemáticas relacionadas con el desempeño de los docentes en el aula, con las mediaciones pedagógicas utilizadas, con los desarrollos académicos, investigativos y de proyección social específicos directamente comprometidos con el alcance del propósito y perfil de formación previamente definidos. Se plantea la necesidad de alcanzar una coherencia de las prácticas pedagógicas desarrolladas con las exigencias de un nuevo contexto caracterizado por la intención de contribuir a la paz, la equidad y reconciliación social de los colombianos y colombianas.

El Enfoque EPIS plantea algunos criterios muy integrados a los principios que lo sustentan:

1. Si el proceso curricular es un proceso de investigación hay que desarrollarlo como tal.

2. es producto de la elaboración permanente y colectiva resultado de aproximaciones sucesivas, es necesario vincular a las diversas audiencias (directivos, docentes, estudiantes, egresados, padres de familia, otros,) del proceso formativo en la construcción de estos currículos y en la construcción de este modelo.

3. La investigación como la esencia del EPIS. Se ha insistido a lo largo de este trabajo que los problemas se convierten en los ejes centrales de los procesos formativos alternativos de cara a un nuevo contexto social.

4. Finalmente, la retroalimentación entendida como el trabajo bidireccional del proceso; la idea es romper con esa mirada hegemónica y lineal que considera que el proceso curricular es el desarrollo de una serie de pasos. 
La implementación del EPIS está relacionada con la "des-ideologización del currículo", entendido como el proceso que rompe con la idea que el currículo es resultado de un proceso de "transmisión de conocimientos" y se trabaja en la posibilidad de posicionarlo como un "proceso de investigación permanente".

\section{Referencias bibliográficas}

López, N. (2011). Modernización curricular de la Universidad Surcolombiana. Neiva: Universidad Surcolombiana.

Magendzo, A., \& Pavéz, J. (2015). Educación en Derechos Humanos: una propuesta para educar desde la perspectiva controversial. Recuperado de http://cdhdf.org.mx/wp-content/uploads/2015/ 10/Educaci\%C3\%B3n-en-derechos-humanosMage ndzoPav\%C3\%A9z.pdf

Magendzo-Kolstrein, A., \& Toledo-Jofré, M. (2015). Educación en derechos humanos: Estrategia pedagógica-didáctica centrada en la controversia. Revista Electrónica Educare, 19 (3), $1-16$.

Díaz Villa, M. (1990). De la práctica pedagógica al texto pedagógico. Pedagogía y Saberes, 0(1), 14.27. doi:http://dx.doi.org/10.172 27/01212494.1pys14.27 